\title{
English as the International Language of Research
}

\author{
John Swales \\ University of Michigan, \\ Ann Arbor, USA
}

The annual world output of research papers and scholarly articles is large and increasing, and there is little doubt that English is the medium of publication for the majority of such papers. However, closer analyses of the available data reveal rather few papers from nonnative speakers, especially from the Third World. This imbalance suggests that English is only the International Language of Research in a receptive sense. It needs to become so in a productive sense as well if Third World investment in doctoral scholarship etc. is to remain justified. Unfortunately, the ESP profession has concentrated on undergraduate teaching programmes and rather neglected the teaching of Research English. However, there are now welcome signs of change, which may therefore aid a process of making English a truly international language rather than one over-restricted in terms of publication sources to the Northern Hemisphere.

Approximately half of the researchers who have ever lived are living and working today. In one sense, these scholars and researchers form themselves into a series of over-lapping communities, disciplinary and inter-disciplinary, local, national and international. In another sense, we can consider researchers, whether based in universities, Government research centres or in private companies, as all working the knowledge-manufacturing industry. Just as the products of the automotive industry are cars, buses and trucks, so the products of the knowledge or research industry are articles, research reports and monographs. In fact, the analogy holds up surprisingly well - principally because of the widely-held belief that the research process is incomplete until the work is published and thus made into an available product.

The world output of research papers and scholarly articles is not known, but certainly runs into millions - and possibly into tens of millions - of exemplars each year. It is generally thought by both the researchers and by others such as linguists and translators that the language predominantly used for the dissemination of this enormous volume of research information is English, even though it is rare to find any evidence for this belief. There is some evidence, although it needs circumspect interpretation. Wood (1967) investigated the language of original articles abstracted by the major science Abstracting and Indexing services in 1965 - an investigation that was replicated (as far as possible) using 1981 data by Baldauf and Jernudd (1983a). The advance made by English over those sixteen years is very striking and covers con- 
sistently all the five disciplines examined. Percentages (to the nearest percent) of English language publications are as follows:

$\begin{array}{lccc} & 1965 & 1981 & \text { Gain } \\ \text { Chemistry } & 50 & 67 & 17 \% \\ \text { Biology } & 75 & 86 & 11 \% \\ \text { Physics } & 73 & 85 & 12 \% \\ \text { Medicine } & 51 & 73 & 22 \% \\ \text { Maths } & 55 & 69 & 14 \%\end{array}$

The major European languages (Russian, French, German) declined, whilst Japanese and Chinese increased, although the last from an extremely small 1965 base.

As Baldauf and Jernudd themselves observe, such percentages may, however, be biassed towards English because the Abstracting services are American. Secondly, the 1965 and 1981 figures are not precisely comparable because the Abstracting services have both changed their names and the procedures during the interviewing period as a result of increasing computerization. Thirdly, the sheer volume of research publication means that even very small percentages represent sizeable numbers of papers. For instance, in Chemical Abstracts Search for 1981, the one percent of papers written in Chinese still represents an impressive annual total of about 2,500 Chinese-language papers. In an attempt to counteract English Language bias, Baldauf and Jernudd (1983b) have analysed Aquatic Sciences and Fisheries Abstracts, which is a UNESCO publication based in Zurich and with a global orientation. Yet again, English predominated $(75 \%)$ with French $(5.5 \%)$ and Spanish $(4 \%)$ coming a long way behind.

An alternative technique is to analyse not the language of the research articles themselves (which may well be determined by Journal editorial policy) but the language of the papers and reports cited in the articles. Baldauf (ms) has recently investigated four leading Journals in Cross-cultural Psychology and has found that the percentages of English language citations varied from $87 \%$ to $98 \%$. Rather different results are reported by Lewin and Jordan (1981) in their study of the distribution of citations across Languages in selected Phycology and marine Biology Journals. They comment:

Articles in the American and Indian journals refer predominantly ( $90 \%$ or more of the citations) to papers or books published in English, whereas in Journals published in France, Germany, Japan 
and the Soviet Union, the proportion of English citations falls belows $60 \%$. The differences are made up largely by articles in the language of the country in which the journal is published: French $(29 \%)$, German $(22 \%)$, Japanese $(25 \%)$ and Russian $(67 \%)$, respectively.

The conclusion that we can draw from the portion of the statistical literature I have had space here to review is that English is indeed the strongly dominating language for the communication of research on an international level. Nevertheless, there remain important if threatened national literatures in other languages. The threat is epitomized in Lewin and Jordan's observation that "we have been told by both German and Chinese scientists that for their really important publications they use English wherever possible". The threat can be seen in Germany where a number of journals have become anglicised: for instance, Archiv fur Mikrobiologie is now Archives of Microbiology. The threat to French as a scientific language has been taken sufficiently seriously to warrant the establishment of a Presidential Commission charged with halting its decline. Certainly, Wood (1967) was quite wrong when he predicted that as the underdeveloped areas caught up technologically, the proportion of foreign-language literature would increase rather than decrease. Nor are radical alternatives credible. The General Conference of UNESCO in Montevideo in 1954 authorised the Director General "to follow the current evolution in the use of Esperanto in Science". That particular evolution has not taken place.

The discussion so far should provide much comfort to those who are native or near-native speakers of English, or who are concerned with studying it, teaching it or promoting it. Yet I fear the fair English rose contains a canker. In order to see this, we need to look behind the crude figures presented so far and ask two questions "where is the research published in English being done"; and "who is doing it?"

Baldauf and Jernudd's analysis of a sample of the ASFA Fisheries Literature provides a tentative answer to the first question. We must remember that they found the $75 \%$ of the articles abstracted were written in English. They then calculated, on the basis of the institutional affiliation of the first author, that four-fifths of these English-language articles report work done in countries where English is either the national language or an official language. Two-thirds of the remaining $20 \%$ appeared as outcomes of international forums or of the work of multinational commissions such as the International Whaling Commission. There remained a residue of 40 English language papers out of 666 that were submitted from locations in which English was a foreign language, and very few of these were outside western Europe and Japan. 
The second question really relates to the issue of whether the authors of articles written in English are native speakers (NS) of English or nonnative speakers (NNS). In order to try and get at this issue without undertaking the labour of communicating directly with individual authors, I have tried to develop a procedure for identifying the NS/NNS status of authors based on a scrutiny of their publications. The procedure scores a maximum of six elements: first name; last name; permanent institutional affiliation; the language(s) of citations; the language(s) of self-citations; NS/NNS status-relevant footnotes or endnotes (translation, acknowledgements of linguistic help, visiting affiliation, source of research grant etc). On a preliminary trial, inter-scorer reliability was $90 \%$. It has also been tried out by two independent scorers on a section of the ESP literature (with which I am familiar) and few cases of mistaken NS/NNS status emerged.

The scoring procedure was applied to randomly-selected British and American Journals from two fields, Health Sciences and Economics. The results in percentages are as follows:

$\begin{array}{cccc} & \begin{array}{c}\text { NS or } \\ \text { Probably NS }\end{array} & \begin{array}{c}\text { NNS or } \\ \text { Probably NNS }\end{array} & \begin{array}{c}\text { Uncertain } \\ \text { Status }\end{array} \\ \begin{array}{c}\text { Health Sciences } \\ (\mathrm{N}=434)\end{array} & 72 & 23 & 5 \\ \begin{array}{c}\text { Economics } \\ (\mathrm{N}=189)\end{array} & 88 & 9 & 3\end{array}$

This is not the place to speculate about the difference between the two fields. The important issue is the location of authors categorized by the scoring procedure as being non-native speakers of English or probably non-native speakers of English. Of the 117 locations traced, 42 were in Western Europe, 22 in the Nordic Countries, 12 in Japan, and 11 in Eastern Europe or Russia, and 9 in North American. There were 21 Third World locations, but eleven of these were from institutions in the Indian sub-continent with its strong tradition of using English as the language of scholarship, and five from Israel, where the data is particularly suspect because of the large amount of US-Israeli academic traffic. Thus, there remain but five papers of clear NNS Third World provenance, four from Latin America and one from Korea.

If my own findings and those of Baldauf and Jernudd are to be confirmed by further and larger-scale investigations, they are very worrying for all those concerned with the future of English as the international language of research. They would seem to imply either one of two things. On the one hand, they suggest that research is largely the preserve of countries where English is either the national language or the of ficial 
language, of countries with an international language of scholarship such as Japan or Russia, or of those individuals who enter into international collaborative networks. Certainly, they indicate very low levels of research in the Arab World, Latin America, South East Asia and Francophone Africa. On the face of it, this seems unlikely given the fact that publication in journals is the standard way of gaining promotion in academic and research fields throughout the world.

On the other hand, then, the results suggest that research in the non-anglophone Third World may well be taking place, but little of it is finding its way into the journals that come to the attention of the major and highly efficient abstracting services. Whichever view we adopt, we seem to be faced with a further instance of North-South imbalance. And in turn we are faced with serious and hard questions about the effectiveness of the massive investment by hard-pressed Third World countries in doctoral scholarships held by their nationals in the USA and Europe, and about the long-term scientific and developmental value of the large numbers of research and advanced training awards offered to Third World nationals by British, American, Russian and European governments and other agencies. Hence, the canker in the rose.

At present, we can only guess at the reasons for the relative absence or invisibility of non-Anglophone Third World research. Probably the research environments are less supportive than in the West. Very probably, there exists considerable editorial bias against submissions from out of the way places. Very probably, there are additional language obstacles facing non-native speakers of English, which may be increased by cross-cultural mismatches about the appropriate length, style and organization of research reporting. The first two of these putative reasons the EFL profession can do little about; the third is very much its responsibility.

Unfortunately, EFL teachers and ESP practitioners have, for all sorts of highly understandable reasons, tended to concentrate on English for science students rather than on support for science staff and researchers. Nevertheless, there is a valuable literature in the Sociology of Science that has been largely neglected by language teachers concerned with Research English; Bazerman (1983) provides an excellent review of this work. More particularly, the books by Knorr-Cetina (1981) and Gilbert and Mulkay (1984) offer fascinating insights into how private research is transformed into public (and published) account. In a recent paper, Bazerman (ms) has studied how a group of established physicists read articles in their field. Based only on the names and locations of authors and on key items in the title "the reader is actually placing the article within his or her personal map or schema of the field ... some items loom large and must be investigated in detail, while others seem to 
fall off the end of the known personal universe . . . Frequently the in terviews would read backwards, or jump back and forth as one section raised questions about earlier ones. They in general did not anticipate that articles were to be read sequentially'. All in all, much of this work suggests that the 'real-world' Research drafting and reading processes are based on considerations and strategies rather far removed from those we have traditionally assumed in designing Technical Writing and Study Skills courses.

Independently of this work in the Sociology of knowledge, the ESP profession has in recent years begun to take a more serious interest in Research English. James (1984) has produced a splendid longitudinal study of a Latin American student's struggles with writing his doctoral thesis, and textual and discoursal analyses are on the increase. There have been a number of investigations into particular features of the genre of the research paper such as Tarone et al (1981) and Hill et al (1982); further, those parts of research papers thought to present greatest difficulty to both NS and NNS writers have been given particular attention (Swales 1981, 1983; Mackinlay, 1983).

Although an enormous effort needs to be made, especially in the Third World, I feel that the English teaching profession is becoming ready to offer its own small but important contribution towards making English a real International language of Research, rather than allowing it to remain (in productive terms at least) as primarily a vehicle for the dissemination of research results within the northern hemisphere. Without that effort, we will in effect continue to consolidate rather than undermine imbalances in the world; and without that effort, the future of English as the World's premier scholarly language may be shorter lived than otherwise. Of course, we cannot really tell how extensive that future potentially is. However, history suggests that language of publication is affected by perceptions of where the most exciting work is taking place, and thus much will depend on future research-language patterns around the so-called 'Pacific Rim' - in California, Mexico, Singapore, China, Korea and Japan.

\section{References}

Baldauf, R.B. and Jernudd, B.H. 1983. Language of Publication as a variable in Scientific Communication. Australian Review of Applied Linguistics 6, 1.

Baldauf, R.B. and Jernudd, B.H. 1983. Language Use Patterns in the Fisheries Periodical Literature. Scientometrics 5, 4.

Baldauf, R.B. (ms) Language use in the cross cultural Psychology Literature: Network patterns and individual choices. 
Bazerman, C. 1983. Scientific Writing as a Social Act: A Review of the Literature of the sociology of Science. New Essays in Technical and Scientific Communication: research, theory and practice, Baywood, N.Y.

Gilbert, G.N. and Mulkay, M. 1984. Opening Pandora's Box, CUP.

Hill, S., Soppelsa, B. and West, G. 1982. Teaching ESL students to Read and Write Experimental-Research Papers, TESOL Quarterly, 16, 3.

James, K. 1984. The Writing of Theses by Speakers of English as a Foreign Language: The results of a case study. ELT Documents 117, Pergamon.

Knorr-Cetina, K. 1981. The Manufacture of Knowledge, Pergamon.

Lewin, R. and Jordan, D. 1981. The Predominance of English and the Potential use of Esperanto for Abstracts of Scientific Articles, Science and Scientists, (Ed. Kageyama, M. et al), Japan Scientific Societies Press.

McKinlay, J. 1983. An Analysis of the Discussion Section of Medical Journal Articles, M.A. dissertation, University of Birmingham.

Swales, J. 1981. Aspects of Article Introductions, LSU, Aston.

Swales, J. 1983. Developing Materials for Writing Scholarly Introductions. Case Studies in ELT, Collins.

Swales, J. (ms) English Language Papers and author's First Language: Preliminary Explorations.

Tarone, E., Dwyer, S., Gillette, S., and Icke, V. 1981. On the use of the passive in Two Astrophysics Journal Papers, The ESP Journal, 1, 2.

Wood, D. 1967. The Foreign-Language problem facing scientists and technologists in the United Kingdom - Report of a recent Survey, Journal of Documentation, 23, 2. 